\title{
Alejandría: archivo electrónico y físico integrado desarrollado para universidades
}

\section{Nicolás Manero Carbó}

4TIC

\section{Resumen}

Se presenta Alejandría, plataforma de gestión archivística específicamente pensada para archivos universitarios. Alejandría fue diseñada originalmente basándose en los requisitos del Archivo de la Universitat de Girona, aunque con la intención de que pudiera adaptarse a cualquier universidad española. Con la participación, desde 2016, de cuatro nuevos archivos universitarios, se ha establecido un grupo de trabajo en el que se consensúan las mejoras a implantar. Gracias al trabajo en equipo, durante el año 2017 se han conseguido diversos logros relativos a la homogeneización de políticas y la eficiencia del sistema.

\section{Palabras clave}

Archivo electrónico; Archivo físico; Archivo híbrido integrado; Archivo en universidades; eEMGDE v2; Expediente electrónico; ENI; Depósitos físicos

Cita recomendada: Manero Carbó, N. (2018). Alejandría: archivo electrónico y físico integrado desarrollado para universidades. En El archivo electrónico en la administración digital: 23 Jornadas de Archivos Universitarios, 21-23 de junio de 2017, A Coruña (pp. 107-111).

DOI capítulo: https://doi.org/10.17979/spudc.9788497496803.107 DOI libro: https://doi.org/10.17979/spudc.9788497496803 
La plataforma Alejandría surge de la necesidad del Archivo de la Universitat de Girona (UdG) de poder gestionar todos los depósitos físicos de los que dispone. Su propósito era tener una única aplicación con la que poder controlar toda la documentación archivada, con independencia de su soporte (físico o electrónico). Además, se quería que estuviera adaptada específicamente a las necesidades de una universidad, ya que la mayoría de aplicaciones de gestión de archivo son de ámbito múltiple y no especializadas en el entorno universitario.

Para poder alcanzar el objetivo, la UdG contó con la empresa 4TIC para el análisis de la solución y su posterior desarrollo.

El proyecto se estructuró en 4 fases, teniendo como principal objetivo conseguir un producto especializado para universidades que fuese totalmente integrado:

1. Desarrollar un módulo de gestión de depósitos físicos en el que se incluyera, exclusivamente, la gestión de las estructuras físicas, los elementos de modelado y los contenedores, pero en ningún caso el contenido.

2. Generar un módulo para poder gestionar la documentación electrónica: ficheros, metadatos y tablas de soporte.

3. Desplegar un módulo para poder gestionar la documentación física: metadatos y localización integrada con el módulo de depósitos físicos.

4. Preparar un módulo para poder controlar la retención y el expurgo de toda la documentación de la universidad; además de facilitar la integración con los trámites administrativos online de transferencias, eliminaciones, préstamos, consultas, reactivaciones, devoluciones y prórrogas. 
Durante la primera fase, solamente se habló de estanterías, armarios, cajas, DIN A4 y cintas, y de cómo la UdG podría generar estas estructuras de forma totalmente dinámica y sin depender de proveedores externos en ningún caso.

Se posibilitó la gestión de múltiples depósitos de forma totalmente personalizable y que, con la misma aplicación, se pudiesen obtener informes de ocupación de espacios y reubicar contenedores en cualquier momento.

El desarrollo en esta fase tuvo en cuenta principalmente tres puntos, que se han ido aplicando en las fases posteriores:

- Evitar que la universidad dependiera de entidades externas para poder gestionar la información, y que pudiera así ser plenamente autónoma.

- Diseñar la aplicación pensando en un uso global, de forma que sus usuarios potenciales fueran todas las universidades españolas y, por tanto, sin que fuera personalizada y exclusiva para la UdG.

- Integrar Alejandría con el resto de aplicaciones de la universidad que lo requirieran, gracias a una capa de servicios web.

En la segunda fase se entró de pleno en la gestión de la propia documentación, en este caso la electrónica. Se definieron los objetos documentales a utilizar, la relación entre ellos, los modelos de metadatos a contemplar y, por último, el comportamiento de estos con cada uno de los objetos implicados.

Los objetos documentales definidos fueron los siguientes:

- Fondo

- Clase

- Serie 
- Unidad documental compuesta

- Unidad documental simple

- Volumen

- Documento simple

Se empezó a utilizar una primera versión de esquema de metadatos, definido por la Generalitat de Cataluña y basado en el e-EMGDE. A continuación, se estableció el comportamiento de los metadatos para todos los casos: cuándo eran obligatorios, repetibles o heredables, entre otros.

Al finalizar esta fase, la plataforma ya permitía trabajar con documentación electrónica, insertar sus metadatos, guardar la auditoría de operaciones y obtener las firmas electrónicas de los documentos para guardarlas como metadatos.

En la tercera fase, se continuó con el trabajo realizado en la segunda, pero de forma adecuada a la documentación física. Se ampliaron los metadatos para dar soporte a la localización y el contenido físico. Se integró completamente con el módulo de depósitos físicos, permitiendo saber, por ejemplo, la ubicación de un expediente (en qué estantería o caja está). De la misma forma, desde el punto de vista del depósito, la aplicación marca como "ocupado" el lugar donde está almacenado ese expediente, para evitar, así, poner más documentación en la misma localización.

Finalmente, en la cuarta y última fase del proyecto se analizó y amplió la plataforma con un módulo de gestión de las políticas de conservación y expurgo. De esta forma, se consiguió que no fuera necesario mantener un calendario de conservación independiente. Gracias a esta fase, la plataforma ya dispone de un sistema de avisos que permite informar al archivero/a sobre qué documentación está pendiente, por ejemplo, de eliminar o conservar, y también sobre de qué documentación está en préstamo, en consulta o en transferencia desde la fase activa. 
A finales de 2016 se han unido al proyecto otras cuatro universidades: Universitat de Lleida, Universitat de Vic, Universitat Rovira i Virgili y Universitat Oberta de Catalunya. Con todas ellas se ha formado un grupo de trabajo, de forma que las mejoras o necesidades sobre la aplicación se consensúan conjuntamente. Así, y gracias al trabajo en equipo, durante este año 2017 se han conseguido, entre otros, los siguientes logros:

- Adecuación del modelo de metadatos al e-EMGDE2.

- Generación de índice y expediente electrónico, en formato ENI.

- Aplicación de escritorio para poder sincronizar los documentos con el servidor.

- Exportar la documentación pública para poder publicarla en el portal web o de transparencia.

\section{Conclusiones}

Las principales ideas que se derivan del desarrollo de este proyecto son las siguientes:

- Homogeneización del trabajo entre todas las universidades, bajo unos objetivos y términos legales comunes.

- Reducción de costes.

- Integración en una única plataforma de todas las necesidades de archivo.

- Definición de un roadmap común, adaptado a las necesidades de la universidad española. 